\title{
Uso de fertilizante de liberação lenta na produção de mudas de batata-doce em bandeja
}

\author{
Use of slow-release fertilizer on the production of sweet potatoes \\ plantlets in tray
}

\author{
Amarílis Beraldo Rós ${ }^{1 *}$; Humberto Sampaio de Araújo ${ }^{2}$; Nobuyoshi Narita ${ }^{1}$
}

Resumo

A produção de mudas em recipientes geralmente demanda a utilização de fertilizantes. Assim, o objetivo deste trabalho foi avaliar a produção de mudas de batata-doce em bandeja com utilização de fertilizante de liberação lenta. $\mathrm{O}$ experimento foi conduzido, sob viveiro telado, em esquema fatorial 5 x 5 , com cinco doses do fertilizante de liberação lenta NPK 19-06-10 $(0,50,100,150$ e 200 g por $25 \mathrm{~kg}$ de substrato) e cinco tempos de permanência das mudas em bandeja (14, 28, 42, 56 e 70 dias após plantio das estacas). Foram avaliados número e massa de matéria seca de raízes e folhas. O número de raízes não foi influenciado pela adição de fertilizante. De maneira geral, até a maior dose utilizada não houve prejuízo ao crescimento das mudas. Logo, a adição do fertilizante favorece o crescimento de mudas de batata-doce, sendo que a dose de $200 \mathrm{~g}$ por $25 \mathrm{~kg}$ de substrato promove os melhores resultados.

Palavras-chave: Ipomoea batatas, enraizamento, estaca herbácea, multiplicação, substrato

\begin{abstract}
The production of plantlets in containers generally requires the use of fertilizers. The aim of this study was to evaluate the production of sweet potato in styrofoam trays using slow-release fertilizer. The experiment was carried out, under a screen-protected nursery, in a factorial scheme $5 \times 5$, with five doses of slow-release fertilizer NPK 19-06-10 $(0,50,100,150$ e $200 \mathrm{~g}$ per $25 \mathrm{~kg}$ de substrate $)$ and five times of plantlets permanence in tray $(14,28,42,56$ and 70 days after planting the cuttings). The number and dry matter of roots and leaves were evaluated. The number of roots was not influenced by fertilizer addition. In general, there is not damage to plantlets growth until the highest dose used. Therefore, the fertilizer addition increases the sweet potato plants growth and the dose of $200 \mathrm{~g}$ per $25 \mathrm{~kg}$ of substrate is responsible for the best results.
\end{abstract}

Key words: Ipomoea batatas, rooting, herbaceous cuttings, multiplication, substrate

\footnotetext{
${ }^{1}$ Drs. em Agronomia, Pesquisadores Científicos da Agência Paulista de Tecnologia dos Agronegócios, APTA, Polo Alta Sorocabana. Presidente Prudente, SP. E-mail: amarilis@apta.sp.gov.br; narita@apta.sp.gov.br

${ }^{2}$ M.e em Agronomia, Pesquisador Científico da APTA, Polo Extremo Oeste, Andradina, SP. E-mail: humbertosaraujo@apta. sp.gov.br

* Autor para correspondência
} 


\section{Introdução}

A implantação da cultura da batata-doce (Ipomoea batatas (L.) Lam.) ocorre por meio do uso de material vegetativo. Esse material pode ser obtido de ramas de lavouras comerciais ou de plantas cultivadas em viveiro.

Para implantação do viveiro devem-se utilizar raízes tuberosas ou ramas de plantas produtivas e sadias, visto que a seleção de materiais com boa sanidade favorece o incremento da produtividade da cultura. Segundo Rós, Narita e Hirata (2011), a utilização de ramas de batata-doce oriundas de matrizes isentas de vírus incrementaram a produtividade da cultura em aproximadamente $55 \%$, sem alteração de outras práticas culturais ou utilização de insumos.

A produção de mudas de batata-doce em bandejas contendo substrato comercial é viável (RÓS; NARITA, 2011) podendo ser utilizada para a obtenção de plantas matrizes, mas deve-se determinar se há necessidade de complementar tal substrato com fertilizantes, pois os substratos comerciais geralmente apresentam boas características físicas, mas podem não conter e disponibilizar os nutrientes necessários às mudas por período adequado.

Assim, a realização de adubações que auxiliem o crescimento e o desenvolvimento das mudas pode ser necessária, podendo contribuir para a redução de custos de produção pelo menor tempo de permanência das mudas no viveiro. Uma alternativa é a utilização de fontes de fertilizante que apresentem liberação lenta dos nutrientes, permitindo a disponibilidade contínua e, portanto, menor possibilidade de deficiência, dispensando aplicações parceladas de outras fontes, reduzindo os custos operacionais (MENDONÇA et al., 2008). Fertilizantes de liberação lenta dos nutrientes apresentam seus grânulos de fertilizantes envoltos por membrana termosensível que é dissolvida de forma gradativa em função de variações de temperatura, independentemente da quantidade e qualidade da água aplicada (JOSÉ; DAVIDE;
OLIVEIRA, 2009), sendo que a longevidade préestabelecida da liberação de nutrientes é mantida com temperatura média de $21^{\circ} \mathrm{C}$ (EVERRIS, 2012).

Backes et al. (2007), que trabalharam com mudas de pimenta transplantadas em vasos com substrato comercial com diferentes doses de fertilizante de liberação lenta, verificaram que o uso de fertilizante favorece o crescimento das mudas e diminui inclusive o período de tempo para atingir seu ponto comercial. Serrano, Cattaneo e Ferreguetti (2010) também verificaram maior crescimento de mudas de mamoeiro em substrato contendo fertilizante de liberação lenta, bem como as mudas apresentaram adequado estado nutricional.

O objetivo deste trabalho foi avaliar a produção de mudas de batata-doce cultivadas em bandejas com utilização de diferentes doses de fertilizante de liberação lenta.

\section{Material e Métodos}

O experimento foi conduzido em ambiente de viveiro com tela anti-afídeo situado na Agência Paulista de Tecnologia dos Agronegócios, Polo Alta Sorocabana, no Município de Presidente Prudente, entre agosto e outubro de 2008.

Foram utilizados segmentos de ramas de batatadoce com dois nós, obtidos de plantas da variedade Londrina, cultivadas a campo. Os segmentos foram retirados da porção apical das ramas (até 0,6 m). As folhas foram retiradas com tesoura de poda, tomando-se o cuidado de não ferir as gemas. Cada segmento foi pesado, tendo-se selecionado aqueles com massas semelhantes. Os segmentos foram imersos em solução de $5 \mathrm{ml}$ por L de Carbendazin $50 \% \mathrm{~m} / \mathrm{v}$ por 10 minutos, para evitar doenças fúngicas.

Os segmentos tiveram sua gema basal inserida em substrato com as diferentes doses do fertilizante 19-06-10 de Osmocote (mini-prill) com liberação de todos os nutrientes entre três a quatro meses: 0,50 , 100,150 e 200 g por $25 \mathrm{~kg}$ de substrato comercial 
Plantmax (substrato a base de vermiculita acrescido de casca de Pinus $s p$ ). Foram utilizadas bandejas de poliestireno expandido com 72 células $(11 \mathrm{~cm}$ de altura, $5 \mathrm{~cm}$ nas laterais e volume de $\left.91 \mathrm{~cm}^{3}\right)$, recipientes adequados para a produção de mudas de batata-doce, segundo Rós e Narita (2011).

As bandejas permaneceram a $0,5 \mathrm{~m}$ do chão, sobre bancada formada por arame, o que permitiu a poda natural das raízes das mudas por desidratação. O material foi irrigado duas vezes ao dia por todo o período do experimento. Cada bandeja foi composta por um tratamento (dose) e como as bandejas possuem 12 linhas de 6 células, foram coletas as quatro plantas centrais das $2^{\mathrm{a}}, 4^{\mathrm{a}}, 6^{\mathrm{a}}, 8^{\mathrm{a}}$ e $10^{\mathrm{a}}$ linhas, em cada tempo de permanência: 14, 28, 42, 56 e 70 dias após plantio (DAP), respectivamente. Foram avaliados número e massa de matéria seca de raízes e folhas. Para a quantificação do número de raízes, foram consideradas aquelas que saíam diretamente do segmento de dois nós, e para o número de folhas, aquelas totalmente abertas. Para a obtenção da massa de matéria seca, o material colhido, tanto da parte aérea como das raízes, foi acondicionado em saco de papel e colocado em estufa com circulação forçada de ar mantida à temperatura de $65^{\circ} \mathrm{C} \pm 3{ }^{\circ} \mathrm{C}$, até a obtenção de valores constantes de massa de material seco.

O delineamento experimental adotado foi inteiramente ao acaso em esquema fatorial $5 \times 5$, sendo 5 doses de fertilizante de liberação lenta 1906-10 e cinco tempos de permanência, com três repetições.

Os dados relativos à massa de matéria seca de folhas e de raízes foram transformados mediante emprego da equação $(x+1)^{1 / 2}$, em função da presença de valores próximos a zero. Os dados obtidos foram submetidos a análises de variância e as médias foram ajustadas a equações de regressão polinomial. O critério para a escolha do modelo foi a significância pelo teste $\mathrm{F}$ a $5 \%$ de probabilidade de erro e os maiores valores do coeficiente de determinação $\left(\mathrm{R}^{2}\right)$. Os pontos de máximos foram determinados por derivação das equações de regressão.

\section{Resultados e Discussão}

Para a característica número de raízes, houve diferença significativa apenas para o tratamento época, permanecendo o número médio de raízes nas diferentes doses em 5,35 unidades.

O número de raízes das mudas estimado (Figura 1) apresentou acréscimos até o ponto de máximo que ocorreu na data de $70 \mathrm{DAP}$, ou seja, o número de raízes foi ampliado durante todo o período de permanência na bandeja. O número médio de raízes estimado atingiu 7,5 unidades aos 70 DAP.

Figura 1. Número de raízes em função do tempo de permanência das mudas em bandeja.

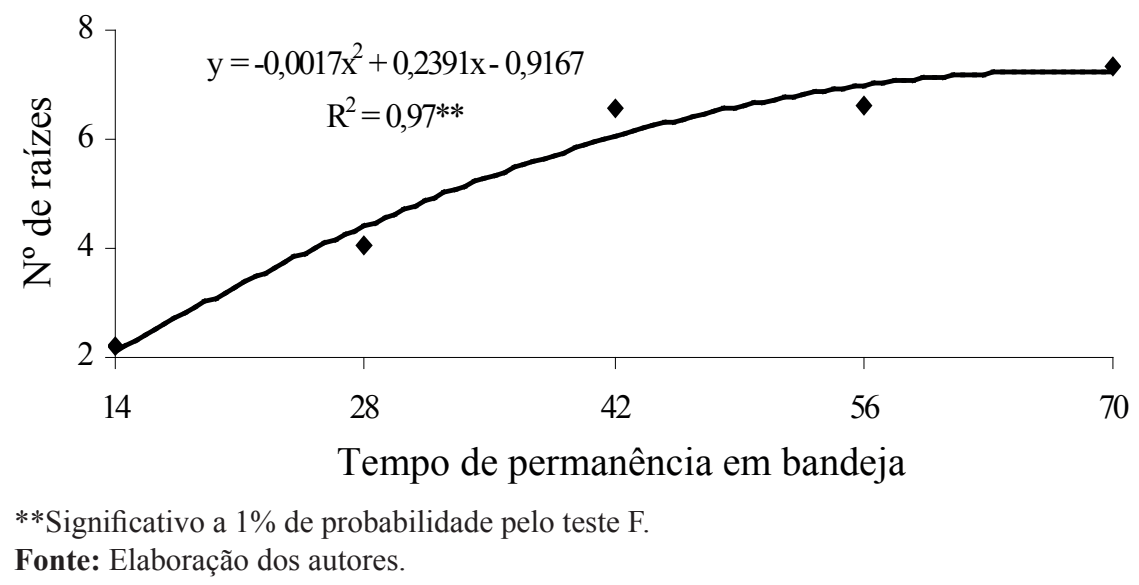


A massa de matéria seca de raízes não foi mudas em nenhuma das doses aplicadas (Figura influenciada pela adição de fertilizante aos 14 2). A resposta linear para essa variável deve-se DAP e 28 DAP. Nos demais tempos: 42, 56 e 70 DAP, houve acréscimo na massa de matéria seca de raízes com o incremento da dose de fertilizante, isto é, nesses tempos de permanência o fertilizante não liberou quantidade de nutrientes prejudicial às provavelmente à liberação lenta desse fertilizante (difusão do nutriente do grânulo para a mistura de substrato), que pode ocorrer em até 4 meses, não permitindo, assim, que se atingisse o ponto de máxima no espaço de resposta.

Figura 2. Massa de matéria seca de raízes de mudas de batata-doce em função de doses de fertilizante de liberação lenta e tempo de permanência 42, 56 e 70 dias após plantio (DAP).
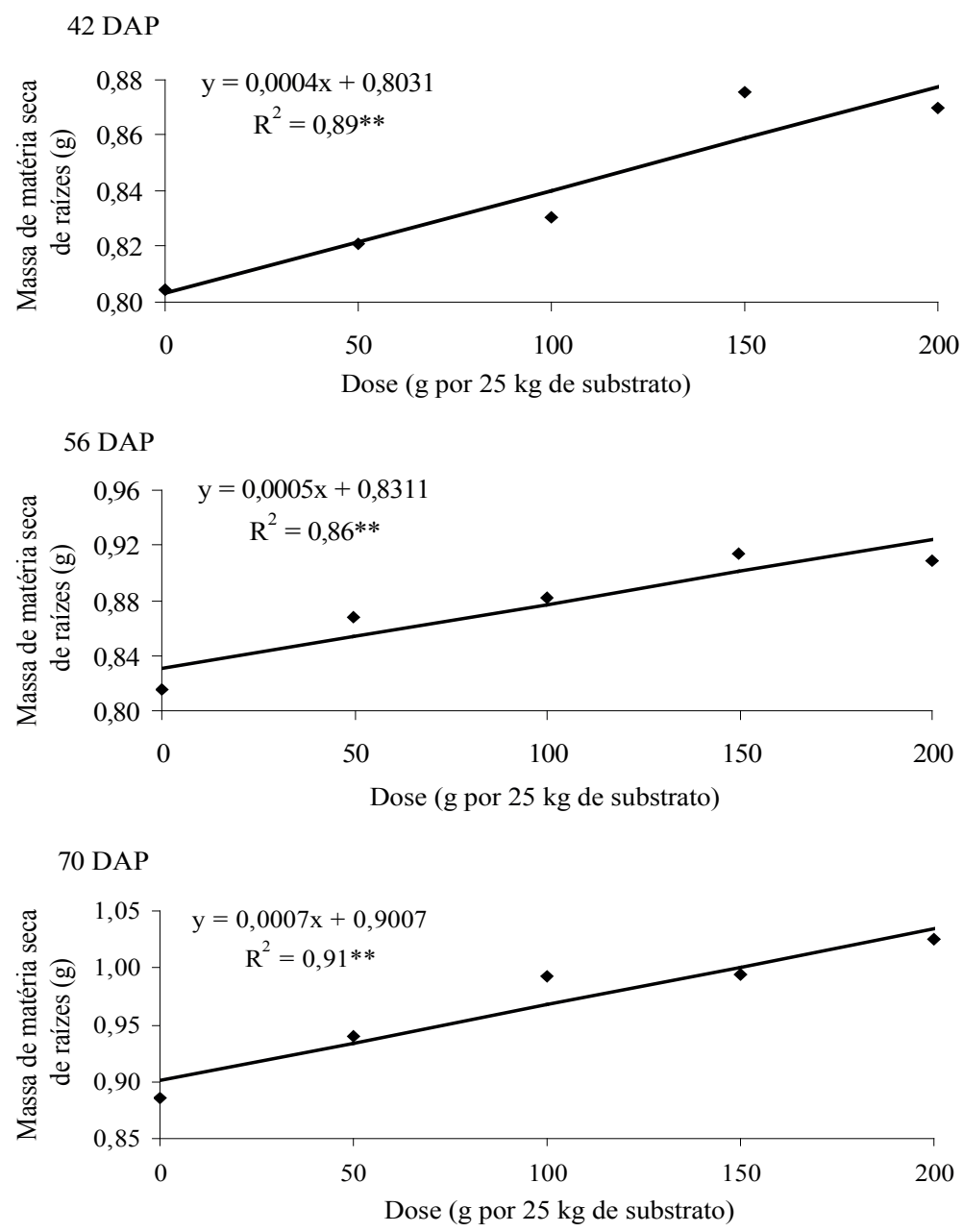

**Significativo a $1 \%$ de probabilidade pelo teste $\mathrm{F}$.

Fonte: Elaboração dos autores.

Mendonça et al. (2004), de maneira semelhante a esse trabalho, observaram que a característica massa de matéria seca de raízes de mudas de maracujazeiro em substratos com fertilizante de liberação lenta apresentou resposta segundo modelo linear crescente em função do incremento das doses. No entanto, Freitas et al. (2011) verificaram que o incremento nas doses de Osmocote promoveu 
resposta estimada linear decrescente na massa de matéria seca de raízes de abacaxizeiros, o que foi justificado pelas mudanças químicas observadas nos substratos à medida que se aumentavam as doses do fertilizante de liberação lenta, inclusive diminuição de $\mathrm{pH}$.

Relacionando-se o número e a massa de matéria seca de raízes, verificou-se que embora o número de raízes não tenha sido influenciado pela adição de doses de fertilizante, sua massa de matéria seca foi incrementada com a adição do fertilizante a partir de 42 DAP. Tal fato indica que, a cada incremento na dose de fertilizante, cada raiz individualmente acumulou maior teor de massa de matéria seca, que pode ter sido ocasionado por maior comprimento ou diâmetro das raízes.

Quanto ao número de folhas, a característica foi influenciada a partir de 28 DAP (Figura 3). Aos 28 e 42 DAP, houve resposta linear crescente com o incremento da dose de fertilizante, devido a quantidade de nutrientes liberada pelo fertilizante não ter sido excessiva de maneira a comprometer 0 surgimento de novas folhas. No entanto, aos 56 e 70 DAP, o incremento do número de folhas ocorreu até as doses estimadas aproximadas de 136 e $317 \mathrm{~g}$ de fertilizante por $25 \mathrm{~kg}$ de substrato, respectivamente, demonstrando o efeito negativo do excesso de fertilizante sobre a característica.

Figura 3. Número de folhas de mudas de batata-doce em função de doses de fertilizante e tempo de permanência em bandeja 28, 42, 56 e 70 dias após plantio (DAP).

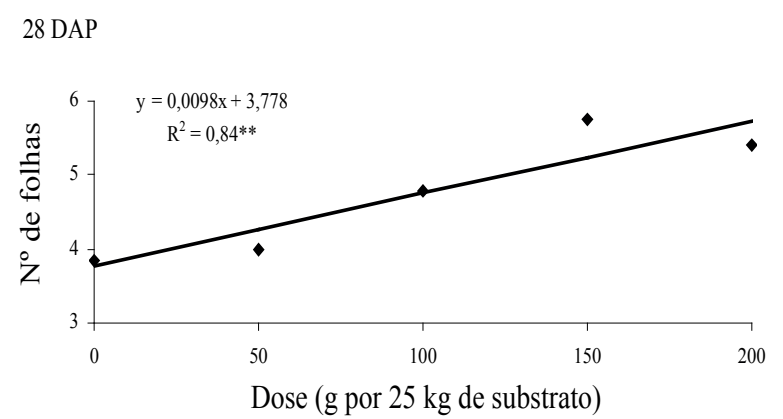

$56 \mathrm{DAP}$

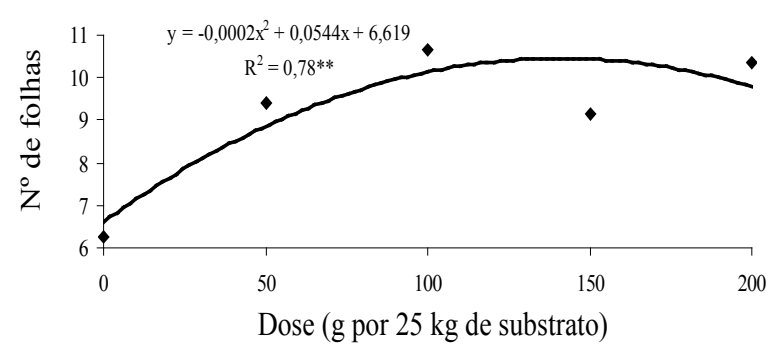

**Significativo a $1 \%$ de probabilidade pelo teste $\mathrm{F}$.

Fonte: Elaboração dos autores.

A resposta do número de folhas a doses de fertilizante segundo modelo quadrático é freqüente. Backes et al. (2007) também verificaram esse comportamento em trabalho com mudas de pimenta
42 DAP

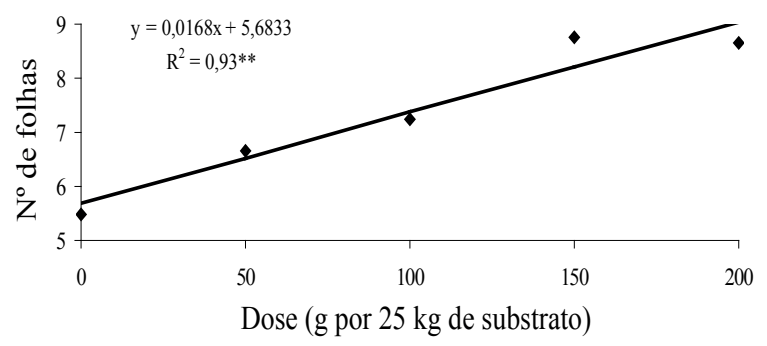

70 DAP

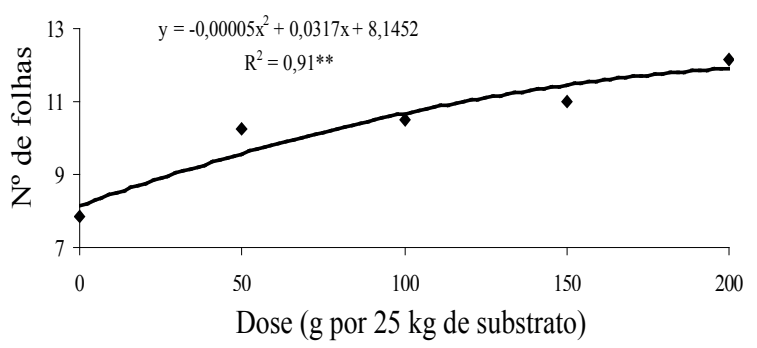

transplantadas em vasos que continham substrato comercial com diferentes doses de fertilizante de liberação lenta. O mesmo ocorreu com mudas de maracujá oriundas de sementes produzidas 
em saquinhos de polietileno (MENDONÇA et al., 2007) e com mudas micropropagadas de abacaxi (FREITAS et al., 2011), no qual as plantas responderam negativamente a doses elevadas de fertilizante.
A massa de matéria seca de folhas, de maneira semelhante à massa seca de raízes, também foi influenciada somente a partir de 42 DAP (Figura 4) e as respostas às doses de fertilizantes foram lineares crescentes, com acréscimo na massa de matéria seca de folhas a cada incremento na dose do fertilizante.

Figura 4. Massa de matéria seca de folhas de mudas de batata-doce em função de doses de fertilizante e tempo de permanência em bandeja de 42, 56 e 70 dias após plantio (DAP).

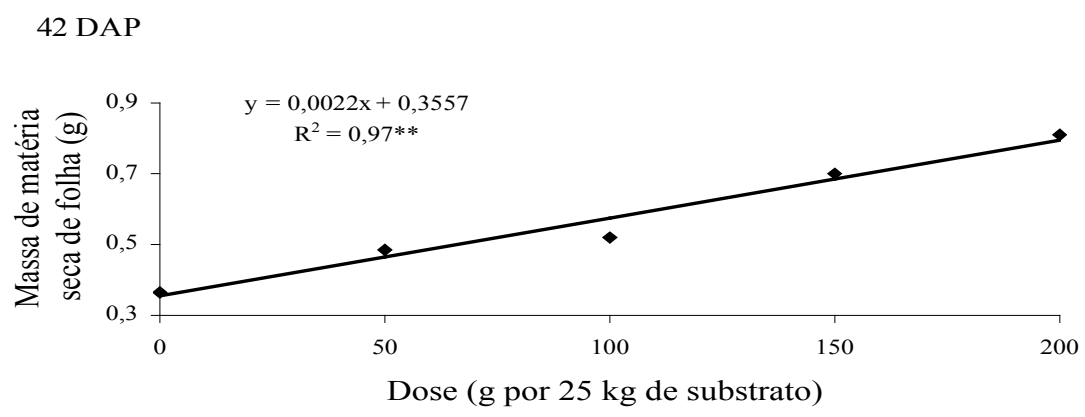

56 DAP

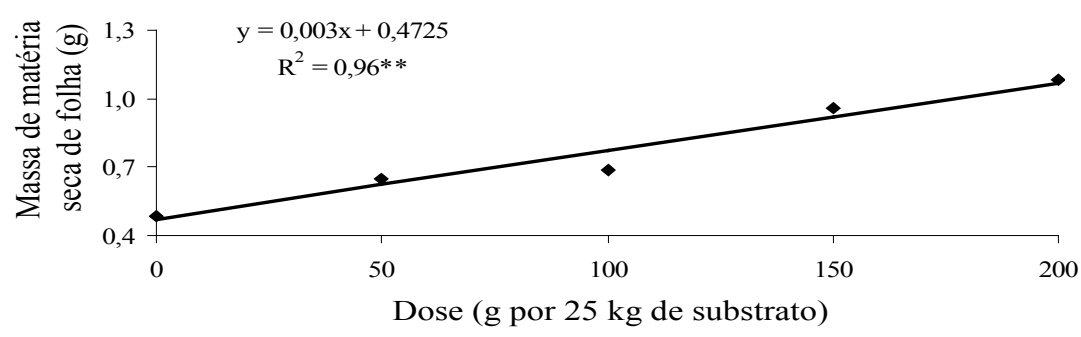

70 DAP

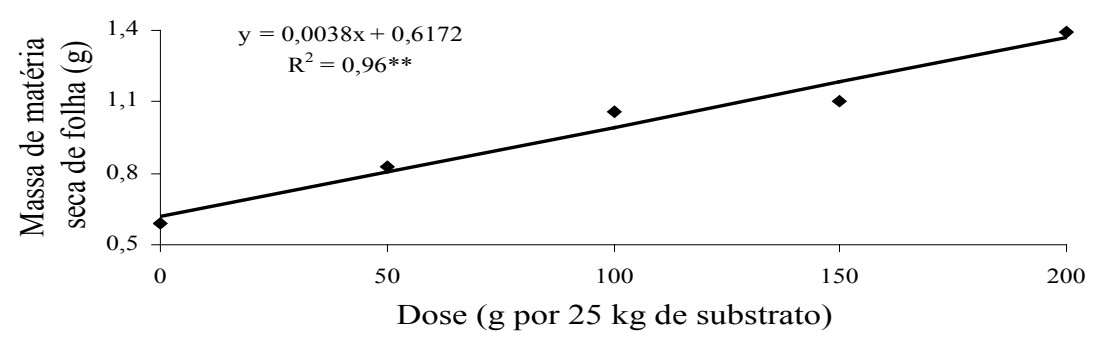

**Significativo a $1 \%$ de probabilidade pelo teste $\mathrm{F}$.

Fonte: Elaboração dos autores.

Mesmo com incremento do número de folhas em função do incremento de doses de fertilizante aos 28 DAP, não houve diferença significativa na massa de matéria seca de folhas em função da dose de fertilizante nesta época. Aos 42 DAP, o incremento na dose do fertilizante resultou em acréscimo no número e na massa de matéria seca de folha. Entretanto, aos 56 e 70 DAP, o número de folhas é reduzido a partir de determinada dose, enquanto sua massa de matéria seca não, o que indica que com a redução do número de folhas, as folhas produzidas acumularam individualmente 
maior quantidade de matéria seca com o acréscimo de doses de fertilizante.

De acordo com estudo com maracujazeiro (PEREIRA et al., 2000), mamoeiro (YAMANISHI et al., 2004), porta-enxerto de citros "trifoliata" (SCIVITTARO; OLIVEIRA; RADMANN, 2004) e dendezeiro (TEIXEIRA et al., 2009), a adição de fertilizante de liberação lenta resulta em incremento de massa de matéria seca e também em maiores teores de nutrientes como $\mathrm{N}, \mathrm{K}$ e $\mathrm{Mg}$.

Dessa forma, pode-se estabelecer que até a maior dose utilizada, $200 \mathrm{~g}$ de $19-06-10$ por 25 kg de substrato, não houve liberação excessiva de nutrientes a ponto de prejudicar as mudas. A redução de folhas aos 56 DAP a partir da dose estimada de 136 g de 19-06-10 por $25 \mathrm{~kg}$ de substrato não comprova efeito negativo de excesso de nutrientes sobre as mudas, pois a massa de matéria seca das folhas continuou sendo incrementada, ou seja, o número de folhas foi reduzido, mas a área do limbo foliar pode ter sido ampliada.

Os resultados obtidos no presente trabalho apresentam-se diferentes dos obtidos por Rós et al. (2011), que, estudando a produção de mudas de batata-doce em bandeja contendo substrato comercial e as doses $0,50,100,150$ e $200 \mathrm{~g}$ de 15-09-12 de Osmocote por $25 \mathrm{~kg}$ de substrato, verificaram que a melhor dose a ser aplicada é de aproximadamente $155 \mathrm{~g}$ por $25 \mathrm{~kg}$ de substrato. A diferença de resultados entre o presente trabalho e o de Rós et al. (2011) deve-se provavelmente ao maior teor de P e K encontrado no fertilizante 15 09-12, que promoveu efeitos negativos em número e massa de matéria seca de raízes e folhas a partir da dose recomendada pelos autores ( $155 \mathrm{~g}$ por $25 \mathrm{~kg}$ de substrato). $\mathrm{O}$ excesso de $\mathrm{P}_{2} \mathrm{O}_{5}$ proporciona elevação da salinidade e toxidez (OLIVEIRA et al., 2006) enquanto a aplicação excessiva de $\mathrm{K}_{2} \mathrm{O}$ promove desequilíbrio nutricional nas plantas, com redução da absorção do $\mathrm{Ca}^{2+}$ e $\mathrm{Mg}^{2+}$, que competem pelo mesmo sitio de absorção que o $\mathrm{K}^{+}$(MARQUES et al., 2011).
Assim, verifica-se que até 14 DAP, se for considerado o número de folhas, ou 28 DAP, se for considerada a massa de matéria seca das mudas, as exigências nutricionais das mudas são supridas pelos nutrientes presentes no substrato, mas a partir desses períodos as mudas respondem à adição do fertilizante NPK 19-06-10 ao substrato com maior crescimento dos sistemas radicular e foliar, podendo ser utilizada a dose de $200 \mathrm{~g}$ do fertilizante por 25 $\mathrm{kg}$ de substrato quando a remoção das mudas das bandejas ocorrer após 28 DAP.

\section{Referências}

BACKES, C.; FERNANDES, F. M.; KROHN, N. G.; LIMA, C. P.; KIIHL, T. A. M. Produção de pimenta ornamental em função de substratos e doses de adubação com fertilizantes de liberação lenta e tradicional. Scientia Agrária Paranaensis, Marechal Cândido Rondon, v. 6, n. 1-2, p. 67-76, 2007.

EVERRIS. Frequently asked Osmocote ${ }^{\circledR}$ questions. 2012. Disponível em: <http://everris.us.com/literature/ frequently-asked-osmocote-questions $>$. Acesso em: 01 out. 2012.

FREITAS, S. de J.; CARVALHO, A. J. C. de; BERILLI, S. da S.; SANTOS, P. C. dos; MARINHO, C. S. Substratos e Osmocote ${ }^{\circledR}$ na nutrição e desenvolvimento de mudas micropropagadas de abacaxizeiro cv. Vitória. Revista Brasileira de Fruticultura, Jaboticabal, v. 33, p. 672-679, 2011. Especial.

JOSÉ, A. C.; DAVIDE, A. C.; OLIVEIRA, S. L. de. Efeito do volume do tubete, tipo e dosagem de adubo na produção de mudas de aroeira (Schinus terebinthifolia Raddi). Agrarian, Dourados, v. 2, n. 3, p. 73-86, 2009.

MARQUES, D. J.; BROETTO, F.; SILVA, E. C. da; CARVALHO, J. G. de C. Dinâmica de cátions na raiz e folhas de berinjela cultivada sobre doses crescentes de potássio oriundas de duas fontes. Idesia, Chile, v. 29, n. 2, p. 69-77, 2011.

MENDONÇA, V.; ABREU, N. A. A. de; SOUZA, H. A. de; TEIXEIRA, G. A.; HAFLE, O. M.; RAMOS, J. D. Diferentes ambientes e Osmocote na produção de mudas de tamarindeiro (Tamarindus indica). Ciência e Agrotecnologia, Lavras, v. 32, n. 2, p. 391-397, 2008.

MENDONÇA, V.; RAMOS, J. D.; GONTIJO, T. C. A.; MARTINS, P. C. C.; DANTAS, D. J.; PIO, R.; ABREU, N. A. A. de. Osmocote e substratos alternativos na produção de mudas de maracujazeiro-amarelo. Ciência 
e Agroetecnologia, Lavras, v. 28, n. 4, p. 799-806, 2004.

MENDONÇA, V.; TOSTA, M. da S.; MACHADO, J. R.; GOULART JUNIOR, S. A. R.; TOSTA, J. da S.; BISCARO, G. A. Fertilizante de liberação lenta na formação de mudas de maracujazeiro amarelo. Ciência e Agroetecnologia, Lavras, v. 31, n. 2, p. 344-348, 2007.

OLIVEIRA, A. P.; SILVA, J. E. L. da; PEREIRA, W. E.; BARBOSA, L. das N.; OLIVEIRA, A. N. P. de. Características produtivas da batata-doce em função de doses de $\mathrm{P}_{2} \mathrm{O}_{5}$, de espaçamentos e de sistemas de plantio. Ciência e Agrotecnologia, Lavras, v. 30, n. 4, p. 611-617, 2006.

PEREIRA, W. E.; LIMA, S. F.; PAULA, L. B. de; ALVAREZ, V. H. Crescimento e composição mineral de mudas de maracujazeiro em função de doses de Osmocote em dois tipos de substratos. Ceres, Viçosa, v. 47, n. 271, p. 311-324, 2000.

RÓS, A. B.; ARAÚJO, H. S. de; NARITA, N.; TAVARES FILHO, J. Uso de fertilizante e tempo de permanência de mudas de batata-doce produzidas em bandejas. Pesquisa Agropecuária Brasileira, Brasília, v. 46, n. 8, p. 845-851, 2011.

RÓS, A. B.; NARITA, N. Produção de mudas de batata-doce a partir de poucas plantas matrizes. Revista Brasileira de Ciências Agrárias, Recife, v. 6, n. 1, p. 8589, 2011.
ROS,A. B.; NARITA, N.; HIRATA, A. C. S. Produtividade de plantas de batata-doce oriundas de matrizes livres de vírus. Pesquisa \& Tecnologia, Campinas, v. 8, n. 4, S1700-S1706, 2011. Disponível em: <http://www. aptaregional.sp.gov.br/index.php/component/docman/ doc_view/833-produtividade-de-plantas-de-batata-doceoriundas-de-matrizes-livres-de-virus?Itemid $=284>$. Acesso em: 29 maio 2012.

SCIVITTARO, W. B.; OLIVEIRA, R. P. de; RADMANN, E. E. Doses de fertilizante de liberação lenta na formação do porta-enxerto 'Trifoliata'. Revista Brasileira de Fruticultura, Jaboticabal, v. 26, n. 3, p. 520-523, 2004.

SERRANO, L. A. L.; CATTANEO, L. F.; FERREGUETTI, G. A. Adubo de liberação lenta na produção de mudas de mamoeiro. Revista Brasileira de Fruticultura, Jaboticabal, v. 32, n. 3, p. 874-883, 2010.

TEIXEIRA, P. C.; RODRIGUES, H. S.; LIMA, W. A. A., ROCHA, R. N. C.; CUNHA, R. N. V.; LOPES, R. Influência da disposição dos tubetes e da aplicação de fertilizantes de liberação lenta, durante o pré-viveiro, no crescimento de mudas de dendezeiro (Elaeis guineensis Jacq.). Ciência Florestal, Santa Maria, v. 19, n. 2, p. 157168, 2009.

YAMANISHI, O. K.; FAGUNDES, G. R.; MACHADO FILHO, J. A.; VALONE, G. de V. Efeito de diferentes substratos e duas formas de adubação na produção de mudas de mamoeiro. Revista Brasileira de Fruticultura, Jaboticabal, v. 26, n. 2, p. 276-279, 2004. 